\title{
PERSEPSI MASYARAKAT TERHADAP KEBERHASILAN LAPANGAN BENTENG SEBAGAI RUANG TERBUKA PUBLIK
}

\author{
Ferdinan Hunter Purba ${ }^{(1)}$, Polin Naibaho(2), Williater Rajagukguk ${ }^{(3)}$ \\ (1) Mahasiswa, Prodi Arsitektur, Fakultas Teknik, Universitas Katolik Santo Thomas Sumatera Utara \\ (2) Staff Pengajar, Prodi Arsitektur, Fakultas Teknik, Universitas Katolik Santo Thomas Sumatera Utara \\ Email: polin.naibaho@ust.ac.id \\ (3) Staff Pengajar, Prodi Arsitektur, Fakultas Teknik, Universitas Katolik Santo Thomas Sumatera Utara
}

\begin{abstract}
Public open space is a vital element in a city because of its presence in high intensity activities. One of the public open spaces in the middle of Medan city is Benteng Square. Benteng Square is included as an active public open space for activities, sports and ceremonies. Benteng Square is owned by the city government of Medan and the management is the Kodim 0201 / BB Medan, but its use is not maximal at this time. Therefore, the research is needed to find out how far the level of success and public perception of Benteng Square. This research is quantitative research. The main data is a questionnaire which is then analyzed descriptively and quantitatively with a Likert scale. The results of the study show that the Benteng Square was successful in its function as a public open space.
\end{abstract}

Keywords: Perception, Open Space

\begin{abstract}
Abstrak
Ruang terbuka publik merupakan elemen vital dalam sebuah kota karena keberadaannya di kawasan yang berintensitas kegiatan tinggi. Salah satu ruang terbuka publik yang berada di tengah-tengah kota Medan yaitu Lapangan Benteng. Jika ditinjau dari kegiatan ruang terbuka publik, Lapangan Benteng termasuk sebagai ruang terbuka publik aktif untuk kegiatan, berolahraga, dan upacara. Lapangan Benteng merupakan milik pemerintah kota Medan dan pihak pengelolanya adalah Kodim 0201/BB Medan. Namun kondisinya saat ini Lapangan Benteng tidak dimanfaatkan baik sebagai ruang terbuka publik. Oleh karena itu perlu dilakukan penelitian untuk menemukan seberapa jauh tingkat keberhasilan dan persepsi masyarakat terhadap ruang terbuka publik. Penelitian ini merupakan penelitian kuantitatif. Data utama merupakan kuisioner yang kemudian dianalisis secara deskriptif-kuantitatif dengan skala nominal dan skala likert. Hasil penelitian menunjukkan bahwa lapangan Benteng dari tingkat kepentingan dan persepsi ternyata berhasil sebagai ruang terbuka publik.
\end{abstract}

Kata-kunci : Persepsi, Ruang Terbuka

\section{Pendahuluan}

Ruang terbuka menurut Plato merupakan wadah yang menampung aktifitas manusia dalam suatu lingkungan yang tidak mempunyai penutup dalam bentuk fisik dan tidak dapat dipisahkan dari manusia (Budihardjo, 1999). Ruang terbukap merupakan salah satu unsur yang penting dalam suatu kota karena mempunyai fungsi-fungsi yang menjadi suatu kebutuhan dari kota. Peran ruang terbuka publik sangat besar dalam meningkatkan kualitas ruang kota karena kebersamaan dalam sosialisasi masyarakat diwadahi oleh ruang terbuka publik. Lapangan Benteng termasuk sebagai ruang terbuka publik yaitu ruang terbuka yang mengandung unsur-unsur kegiatan di dalamnya, antara lain tempat bermain, berolahraga, upacara dan berjalan-jalan. Lapangan Benteng merupakan milik pemerintah kota Medan dan pihak pengelolanya adalah Kodim 0201/BB Medan. 
Berdasarkan hasil observasi pengamatan, di Lapangan Benteng, aktivitas kegiatan di dalam tidak sering terlihat ramai, namun pada event-event tertentu lapangan ini ramai dikunjungi masyarakat. Di dalam Lapangan Benteng ini tersedia fasilitas seperti bangku taman, pohon peneduh, pendopo, area jogging track, tempat parkir, wc, dsb. Jika ditinjau dari sifat ruang terbuka publik, Lapangan Benteng ini merupakan ruang terbuka aktif dan memiliki setiap sudutnya terbuka, sehingga viewnya terbuka dari setiap sudutnya.

Ruang terbuka melayani kebutuhan sosial masyarakat kota dan memberikan pengetahuan kepada pengunjungnya. Ruang terbuka umum dimanfaatkan untuk melakukan berbagai aktivitas dalam kehidupan masyarakat. Pemanfaatannya biasanya untuk aktivitas kerja (rutinitas) maupun aktivitas di waktu senggang. Ruang terbuka dapat memperkenalkan hal-hal dan pengalaman baru melalui interaksi, memberi makna, serta kekuatan dalam kehidupan masyarakat, menjadi penawar setelah sibuk kerja, memberikan kesempatan belajar melalui musik dan hiburan lain yang menjadi program dari fungsi ruang terbuka tersebut

\section{Kajian Pustaka}

Menurut Bimo Walgito (2010: 99), persepsi merupakan suatu proses penginderaan, yaitu merupakan proses diterimanya stimulus oleh individu melalui alat indera atau juga disebut proses sensoris. Menurut Sarlito Wirawan Sarwono (1983:89), persepsi adalah kemampuan seseorang untuk mengorganisir suatu pengamatan, kemampuan tersebut antara lain kemampuan untuk mengelompokkan, dan kemampuan untuk memfokuskan. Oleh karena itu seseorang bisa saja memiliki persepsi yang berbeda, walaupun objeknya sama. Hal tersebut dimungkinkan karena adanya perbedaan dalam hal sistem nilai dan ciri kepribadian individu yang bersangkutan.

Dalam Wikipedia, masyarakat (sebagai terjemahan istilah society) adalah sekelompok orang yang membentuk sebuah sistem semi tertutup (atau semi terbuka), dimana sebagian besar interaksi adalah antara individu-individu yang berada dalam kelompok tersebut. Kata "masyarakat" sendiri berakar dari kata dalam bahasa Arab, musyarak. Masyarakat adalah sebuah komunitas yang interdepeden (saling tergantung satu sama lain).

Menurut Widjaya, masyarakat adalah sekelompok orang yang mempunyai identitas tertentu, dapat dibedakan dengan kelompok lain dan hidup diam dalam wilayah atau daerah tertentu secara tersendiri. Kelompok ini baik secara sempit maupun luas mempunyai perasaan akan adanya persatuan di antara anggota kelompok dan mengangap dirinya berbeda dengan kelompok lain. Mereka memiliki norma, ketentuan, dan peraturan yang dipatuhi bersama sebagai suatu ikatan.

Berdasarkan pengertian persepsi dan masyarakat dapat disimpulkan bahwa persepsi masyarakat adalah suatu proses dimana sekelompok manusia yang hidup dan tinggal bersama dalam wilayah tertentu dan memberikan pemahaman atau tanggapan terhadap hal-hal atau peristiwa yang terjadi dilingkungannya.

Ruang terbuka menurut Project for Public Spaces in New York, (1984 ) adalah bentuk ruang yang digunakan manusia secara bersama-sama berupa jalan, pedestrian, taman-taman, plaza, fasilitas transportasi umum dan lain sebagainya merupakan suatu bagian dari ruang terbuka secara umum. Ruang terbuka menurut plato merupakan wadah yang menampung aktivitas manusia dalam suatu lingkungan yang tidak mempunyai penutup dalam bentuk fisik dan tidak dapat dipisahkan dari manusia baik secara psikologis, emosional ataupun dimensional. Ruang terbuka merupakan aktivitas sosial yang melayani dan juga mempengaruhi kehidupan masyarakat kota.

Pengertian Ruang Terbuka kota secara singkat merupakan suatu ruang publik yang berfungsi untuk kegiatan masyarakat yang berkaitan dengan sosial, ekonomi dan budaya, memiliki fungsi interaksi sosial bagi masyarakat, kegiatan ekonomi rakyat dan tempat apresiasi budaya.

Stephen Carr, dkk (1992) melihat ruang terbuka publik sebagai ruang milik bersama, tempat masyarakat melakukan aktivitas fungsional dan ritualnya dalam suatu ikatan komunitas, baik kehidupan 
sehari-hari maupun dalam perayaan berkala yang telah ditetapkan sebagai sesuatu yang terbuka, tempat masyarakat melakukan aktivitas pribadi dan kelompok.

Ruang terbuka publik juga merupakam bagian dari taman lingkungan. Ruang terbuka publik adalah lahan tidak terbangun di dalam kota dengan penggunaan tertentu. Pertama, ruang terbuka kota didefinisikan sebagai bagian dari lahan kota yang tidak ditempati oleh bangunan dan hanya dapat dirasakan keberadaanya jika sebagian atau seluruh lahannya dikelilingi pagar. Selanjutnya ruang terbuka didefinisikan sebagai lahan dengan penggunaan spesifik yang fungsi atau kualitas terlihat dari komposisinya (Rapuano, 1994).

Menurut Gehl (1987:23) kualitas ruang terbuka publik terbagi dalam 3 (tiga) kategori, yaitu:

1. Necessary Activities (Kegiatan yang Diperlukan)

Kategori ini mencakup seluruh kegiatan yang mau tidak mau harus dilakukan di ruang terbuka publik, misalnya pergi bekerja atau sekolah, berbelanja, menyebarkan surat, menunggu bus atau seseorang, mengantar pesanan dan lain-lain.

\section{Optimal Activities (Kegiatan Optimal)}

Kategori ini mencakup berbagai kegiatan seperti berjalan-jalan menghirup udara segar, berdiri dan mengamati sekitar sambil menikmati suasana atau duduk dan berjemur di bawah matahari dan lain-lain.

3. Social Activities (Kegiatan Sosial)

Kategori ini mencakup semua kegiatan yang bergantung pada kehadiran orang lain dalam ruang publik. Hal ini secara tidak langsung menyatakan bahwa kegiatan sosial secara tidak langsung mendukung kegiatan-kegiatan yang penting (necessary) dan yang bisa dipilih (optimal) memberikan kondisi terbaik dalam ruang publik.

The Project for Public Space, 1999 (Carmona et al. 2003) mengidentifikasi empat atribut utama mengenai keberhasilan ruang terbuka publik, yaitu:

1. kenyamanan dan citra (comfort and image),

2. akses dan penghubung (access and lingkage),

3. penggunaan dan aktifitas (uses and activity),

4. suasana yang ramah/bersahabat (sociability).

\section{Metode Penelitian}

Metode penelitian ini menggunakan metode penelitian deskritif-kualitatif. Penelitian deskriptif adalah penelitian yang dilakukan terhadap variabel mandiri, yaitu tanpa membuat perbandingan, atau menghubungkan dengan variabel yang lain. Jenis penelitian ini bertujuan untuk menggambarkan, meringkaskan berbagai kondisi, berbagai situasi atau berbagai fenomena realitas sosial yang ada di masyarakat yang menjadi objek penelitian.

Teknik pengumpulan data dengan menggunakan data primer dan sekunder, selanjutnya menentukan kriteria penilaian yang dibagi dalam 2 variabel yaitu persepsi masyarakat dan keberhasilan ruang terbuka publik yang disusun dalam format kuisioner dengan jumlah responden 100 orang. Kemudian dianalisis dengan menggunakan Skala Nominal dan Skala Likert.

\subsection{Metode Pengumpulan Data}

Metoda pengumpulan data yang digunakan melalui tahap observasi yang bertujuan untuk mengumpulkan permasalahan yang ada dan menentukan sejumlah variabel melalui alat pengukur wawancara. Pengumpulan data menggunakan 2 proses, yaitu:

1. Pengumpulan data secara langsung (Data Primer) adalah Pengumpulan data dilakukan dengan teknik kuisioner, foto, dan observasi secara langsung. 
2. Pengumpulan data secara tidak langsung (Data Sekunder), yaitu pengumpulan data dengan menggunakan studi literatur dan kajian pustaka ruang terbuka publik. Dalam penelitian ini diperoleh dari berbagai sumber seperti, buku, jurnal, laporan dan lain-lain.

3. Populasi sampling yang digunakan adalah masyarakat kota Medan. Data sampel penelitian yang diambil menggunakan teknik Simple Random Sampling (Sampel acak sederhana) adalah sebuah sampel yang diambil sedemikian rupa sehingga tiap unit penelitian atau satuan elementer dari populasi mempunyai kesempatan yang sama untuk dipilih sebagai sampel. Pada teknik ini seseorang diambil sebagai sampel karena kebetulan orang tadi ada di situ atau kebetulan peneliti mengenal orang tersebut dan seseorang yang mengetahui Lapangan Benteng. Jumlah sampel sebanyak 100 orang berdasarkan rumus Slovin dalam Sudrajat (2002).

\subsection{Metode Analisis Data}

Teknik yang digunakan dalam menganalisis data adalah dengan teknik analisis kuantitatif yang sering disebut juga dengan teknik statistik yang berbentuk angka. Jenis statistika yang digunakan adalah statistika deskriptif. Statistika deskriptif adalah statistik yang digunakan untuk menganalisis data dengan cara mendeskripsikan atau menggambarkan data yang telah terkumpul sebagaimana adanya tanpa bermaksud membuat kesimpulan yang berlaku untuk umum atau generalisasi. Penyajian data dapat dilakukan dengan mencari frekuensi mutlak, frekuensi relatif (mencari persentase), serta mencari ukuran tendensi centralnya yaitu mode, median dan mean.

Analisis data penelitian menggunakan skala Nominal, dan Skala Likert Untuk mengetahui persepsi masyarakat terhadap keberhasilan Lapangan Benteng sebagai ruang terbuka publik, maka perlu diukur Identitas pengunjung dan Pengalaman pengunjung.

\section{Hasil dan Pembahasan}

Analisis data penelitian menggunakan skala Nominal, dan Skala Likert untuk mengetahui persepsi masyarakat terhadap keberhasilan Lapangan Benteng sebagai ruang terbuka publik, maka perlu diukur identitas pengunjung dan pengalaman pengunjung.

Tabel 1. Data mayoritas identitas pengunjung

\begin{tabular}{lllll} 
No & Variabel & Sub Variabel & Freq & $\%$ \\
\hline 1 & Usia & 15-25 Tahun & 33 & 84.6 \\
\hline 2 & Jenis Kelamin & Laki-laki & 21 & 53.8 \\
\hline 3 & $\begin{array}{l}\text { Pendidikan } \\
\text { Terakhir }\end{array}$ & SMA/Sederajat & 29 & 74.3 \\
& & & \\
\hline 4 & Status Pekerjaan & Mahasiswa & 26 & 66.6 \\
\hline 5 & Status Pekerjaan & Tetap (KTP Medan) & 26 & 66.6 \\
\hline 6 & Lama Tinggal di & $>16$ Tahun & 20 & 51.2 \\
& Medan & & &
\end{tabular}

\section{Hasil Tabulasi Silang Data Identitas dan Pengalaman Pengunjung dengan Skala Nominal}

1. Tabulasi Silang Jenis Kelamin dengan Usia menunjukkan dari 39 responden, mayoritas respondennya laki-laki yaitu 23 orang (58.9\%) dengan rata-rata usia 15-25 tahun dengan 33 orang (84.6\%).

2. Tabulasi Silang Pendidikan Terakhir dan Usia dapat diketahui bahwa sebagian besar responden adalah usia 15-25 tahun sebanyak 33 orang (84.6\%) dan sebagian besar pendidikan terakhirnya adalah SMA yaitu 26 orang (66.6\%).

3. Tabulasi Silang Pekerjaan dan usia dapat diketahui bahwa responden merupakan dengan pekerjaan mahasiswa yaitu sebanyak 26 orang (66.6 \%) dan usianya yaitu 15-25 tahun sebanyak 33 orang (84.6\%).

4. Tabulasi Silang Status Kependudukan dan Lama Tinggal dapat diketahui bahwa responden sebagian besar adalah warga Medan yang tetap dengan jumlah 25 orang (64.1\%) dan sebagian besar di 
Medan dengan jangka waktu > 16 tahun dengan 19 orang (48.7\%). dapat diketahui bahwa responden sebagian besar adalah warga Medan yang tetap dengan jumlah 25 orang (64.1\%) dan sebagian besar responden lama tinggal di Medan dengan jangka waktu > 16 tahun dengan 19 orang (48.7 \%).

5. Tabulasi Silang Kapan Berkunjung dan Waktu Kunjungan dapat diketahui bahwa responden berkunjung sebagian besar adalah di hari libur besar yaitu 20 orang (51.2\%) dan waktu kunjungan yang sering dikunjungi adalah pada waktu sore dengan jumlah 20 orang (51.2\%).

6. Tabulasi Silang Kapan Berkunjung dan Banyaknya Kunjungan dapat diketahui bahwa responden berkunjung di hari libur besar yaitu sebanyak 20 orang (51.2\%) dan sebanyak 28 orang (71.7\%) responden yang menyatakan kunjungannya jarang (1 kali dalam sebulan).

7. Tabulasi Silang Waktu Kunjungan dan Lamanya Kunjungan dapat diketahui bahwa waktu kunjungan responden sebagian besar adalah 20 orang (51.2\%) dan lamanya kunjungan responden sebagian besar adalah 18 orang (46.1\%).

8. Tabulasi Silang dengan Siapa Berkunjung dan Banyaknya Kunjungan dapat diketahui bahwa responden berkunjung sebagian besar dengan jumlah 1-3 orang yaitu 21 orang (53.8 \%) dan dengan banyaknya kunjungan responden yaitu 28 orang (71.7 \%) yang menyatakan jarang ( 1 kali dalam sebulan).

9. Tabulasi Silang Sarana Trasportasi dan Waktu Tempuh Berkunjung dapat diketahui bahwa sarana responden yang digunakan sebagian besar adalah kendaraan pribadi yaitu 26 orang (66.6 \%) dan waktu tempuh berkunjung responden yaitu membutuhkan < 45 menit sebanyak 21 orang (53.8 \%).

10. Tabulasi Silang Lamanya Berkunjung dan dengan Siapa Berkunjung dapat diketahui bahwa responden yang berkunjung mayoritas adalah 1-3 orang yaitu 21 orang (53.8 \%) dan lamanya berkunjung responden adalah 1-3 jam dengan jumlah 18 orang (46.1\%).

Tabel 2. Data Mayoritas Identitas Pengunjung Berdasarkan Tingkat Kepentingan (k)

\begin{tabular}{|c|c|c|c|c|c|c|c|c|c|c|c|}
\hline \multirow{2}{*}{ No } & \multirow{2}{*}{ Pertanyaan } & \multicolumn{10}{|c|}{ Kepentingan (k) } \\
\hline & & 1 & $\%$ & 2 & $\%$ & 3 & $\%$ & 4 & $\%$ & 5 & $\%$ \\
\hline 1 & Menarik & 1 & 2.5 & 1 & 2.5 & 7 & 17.9 & 21 & 53.8 & 9 & 23 \\
\hline \multirow[t]{2}{*}{2} & Tingkat & & & & & & & & & & \\
\hline & $\begin{array}{l}\text { Lapangan Benteng untuk } \\
\text { digunakan }\end{array}$ & 0 & 0 & 0 & 0 & 9 & 23 & 16 & 41 & 14 & 35.8 \\
\hline 3 & NYAMAN untuk kegiatan & 0 & 0 & 0 & 0 & 4 & 10.2 & 14 & 35.8 & 21 & 53.8 \\
\hline 4 & BERSIH & 1 & 2.5 & 1 & 2.5 & 0 & 0 & 18 & 46.1 & 19 & 48.7 \\
\hline 5 & TEDUH, SEJUK & 1 & 2.5 & 0 & 0 & 4 & 10.2 & 14 & 35.8 & 20 & 51.2 \\
\hline 6 & MUDAH dicapai & 0 & 0 & 0 & 0 & 5 & 12.8 & 22 & 56.4 & 12 & 30.7 \\
\hline 7 & $\begin{array}{l}\text { KETERSEDIAAN lahan } \\
\text { parkir }\end{array}$ & 0 & 0 & 0 & 0 & 3 & 7.6 & 14 & 35.8 & 22 & 56.4 \\
\hline 8 & $\begin{array}{l}\text { BEBAS masuk dan } \\
\text { berkegiatan }\end{array}$ & 0 & 0 & 0 & 0 & 1 & 2.5 & 20 & 51.2 & 18 & 46.1 \\
\hline 9 & BANYAK aktivitas & 1 & 2.5 & 3 & 7.6 & 4 & 10.2 & 18 & 46.1 & 13 & 33.3 \\
\hline 10 & Fasilitasnya LENGKAP & 0 & 0 & 1 & 2.5 & 3 & 7.6 & 17 & 43.5 & 18 & 46.1 \\
\hline 11 & $\begin{array}{l}\text { PEDAGANG } \\
\text { makanan/minuman }\end{array}$ & 0 & 0 & 6 & 15.3 & 10 & 25.6 & 12 & 30.7 & 11 & 28.2 \\
\hline 12 & $\begin{array}{l}\text { Tingkat KEISTIMEWAAN } \\
\text { Lapangan Benteng }\end{array}$ & 0 & 0 & 1 & 2.5 & 4 & 10.2 & 20 & 51.2 & 14 & 35.8 \\
\hline 13 & MENYENANGKAN & 0 & 0 & 2 & 0 & 5 & 12.8 & 20 & 51.2 & 12 & 30.7 \\
\hline 14 & RAMAI pengunjung & 0 & 0 & 4 & 10.2 & 8 & 20.5 & 17 & 43.5 & 10 & 25.6 \\
\hline 15 & $\begin{array}{l}\text { ACARA event-event di } \\
\text { Lapangan Benteng }\end{array}$ & 0 & 0 & 1 & 2.5 & 5 & 12.8 & 13 & 33.3 & 20 & 51.2 \\
\hline 16 & AMAN dikunjungi & 0 & 0 & 1 & 2.5 & 0 & 0 & 17 & 43.5 & 21 & 53.8 \\
\hline
\end{tabular}

11. Tabulasi Silang Banyaknya Kunjungan dan Kendala Berkunjung dapat diketahui bahwa responden sebagian besar mengunjungi sebanyak 6-10 kali yaitu 33 orang (73.3 \%) dan kendala yang dihadapi pengunjung adalah tidak bebasnya masuk ke Lapangan Benteng Medan yaitu sebanyak 15 orang (33.3\%). 
Tabel 3. Hasil Uji Validitas Item Pertanyaan tentang Kepentingan (k).

\begin{tabular}{|c|c|c|c|}
\hline $\begin{array}{l}\text { Item } \\
\text { Pertanyaan }\end{array}$ & Nilai Korelasi & Nilai R Tabel & Keputusan \\
\hline 1 & 0.678 & 0.325 & Valid \\
\hline 2 & 0.432 & 0.325 & Valid \\
\hline 3 & 0.507 & 0.325 & Valid \\
\hline 4 & 0.413 & 0.325 & Valid \\
\hline 5 & 0.413 & 0.325 & Valid \\
\hline 6 & 0.424 & 0.325 & Valid \\
\hline 7 & 0.548 & 0.325 & Valid \\
\hline 8 & 0.528 & 0.325 & Valid \\
\hline 9 & 0.589 & 0.325 & Valid \\
\hline 10 & 0.554 & 0.325 & Valid \\
\hline 11 & 0.389 & 0.325 & Valid \\
\hline 12 & 0.725 & 0.325 & Valid \\
\hline 13 & 0.706 & 0.325 & Valid \\
\hline 14 & 0.547 & 0.325 & Valid \\
\hline 15 & 0.274 & 0.325 & Tidak Valid \\
\hline 16 & 0.175 & 0.325 & Tidak Valid \\
\hline
\end{tabular}

Berdasarkan tabel diatas dapat diketahui bahwa dari 16 item instrumen pertanyaan yang telah diuji tingkat kevaliditasnya, terdapat 14 item pertanyaan yang datanya valid. Data yang tidak valid, tidak akan dipakai pada tahap pengukuran selanjutnya. Dalam menguji validitas item pertanyaan, peneliti menggunakan bantuan program SPSS ke-23 dengan pertimbangan kaidah keputusan bahwa jika $n_{\text {korelasi }} \leq$ $r_{\text {tabel }}$ berarti tidak valid dan jika $n_{\text {korelasi }}>r_{\text {tabel }}$ berarti valid.

Tabel 4. Data Mayoritas Identitas Pengunjung Berdasarkan Tingkat Persepsi (p)

\begin{tabular}{|c|c|c|c|c|c|c|c|c|c|c|c|}
\hline \multirow{2}{*}{ No } & \multirow{2}{*}{ Pertanyaan } & \multicolumn{10}{|c|}{ Persepsi (p) } \\
\hline & & 1 & $\%$ & 2 & $\%$ & 3 & $\%$ & 4 & $\%$ & 5 & $\%$ \\
\hline 1 & Menarik & 3 & 7.6 & 8 & 20.5 & 14 & 35.8 & 13 & 33.3 & 1 & 2.5 \\
\hline 2 & $\begin{array}{lr}\text { Tingkat } & \text { Kelayakan } \\
\text { Lapangan } & \text { Benteng } \\
\text { untuk digunakan }\end{array}$ & 2 & 5.1 & 10 & 25.6 & 11 & 28.2 & 14 & 35.8 & 2 & 5.1 \\
\hline 3 & $\begin{array}{l}\text { NYAMAN untuk } \\
\text { kegiatan }\end{array}$ & 2 & 5.1 & 5 & 12.8 & 17 & 43.5 & 10 & 25.6 & 5 & 12.8 \\
\hline 4 & BERSIH & 1 & 2.5 & 7 & 17.9 & 12 & 30.7 & 11 & 28.2 & 8 & 20.5 \\
\hline 5 & TEDUH, SEJUK & 2 & 5.1 & 9 & 23 & 10 & 25.6 & 13 & 33.3 & 5 & 12.8 \\
\hline 6 & MUDAH dicapai & 0 & 0 & 5 & 12.8 & 19 & 48.7 & 13 & 33.3 & 2 & 5.1 \\
\hline 7 & $\begin{array}{l}\text { KETERSEDIAAN lahan } \\
\text { parkir }\end{array}$ & 1 & 2.5 & 14 & 35.8 & 14 & 35.8 & 7 & 17.9 & 3 & 7.6 \\
\hline 8 & $\begin{array}{l}\text { BEBAS masuk dan } \\
\text { berkegiatan }\end{array}$ & 2 & 5.1 & 15 & 38.4 & 13 & 33.3 & 7 & 17.9 & 2 & 5.1 \\
\hline 9 & BANYAK aktivitas & 4 & 10.2 & 9 & 23 & 18 & 46.1 & 6 & 15.3 & 2 & 5.1 \\
\hline
\end{tabular}

Tabel 5. Hasil Uji Reliabilitas Item Pertanyaan tentang Kepentingan (k).

\begin{tabular}{llll}
$\begin{array}{l}\text { Item } \\
\text { Pertanyaan }\end{array}$ & Nilai Alpha & Nilai R Tabel & Keputusan \\
\hline 1 & 0.842 & 0.325 & Reliabel \\
\hline 2 & 0.855 & 0.325 & Reliabel \\
\hline 3 & 0.852 & 0.325 & Reliabel \\
\hline 4 & 0.856 & 0.325 & Reliabel \\
\hline 5 & 0.856 & 0.325 & Reliabel
\end{tabular}




\begin{tabular}{lccc}
6 & 0.855 & 0.325 & Reliabel \\
\hline 7 & 0.850 & 0.325 & Reliabel \\
\hline 8 & 0.852 & 0.325 & Reliabel \\
\hline 9 & 0.847 & 0.325 & Reliabel \\
\hline 10 & 0.849 & 0.325 & Reliabel \\
\hline 11 & 0.859 & 0.325 & Reliabel \\
\hline 12 & 0.841 & 0.325 & Reliabel \\
\hline 14 & 0.841 & 0.325 & Reliabel \\
\hline 15 & 0.849 & 0.325 & Reliabel \\
\hline 16 & 0.862 & 0.325 & Reliabel \\
& 0.864 & 0.325 & Reliabel \\
& Sumber: Hasil Pengolahan data dengan alat \\
& \multicolumn{5}{c}{ bantu SPSS-23 }
\end{tabular}

Berdasarkan hasil uji reliabilitas pada tabel diatas menunjukkan bahwa semua item instrumen pertanyaan dinyatakan reliabel. Dalam menguji reliabilitas item pertanyaan, peneliti menggunakan bantuan program SPSS ke-23 dengan pertimbangan kaidah keputusan Product Moment, bahwa jika Nilai Alpha $\leq r_{\text {tabel }}$ berarti tidak valid dan jika Nilai Alpha $>r_{\text {tabel }}$ berarti Reliabel. Setelah data mayoritas item pertanyaan berdasarkan tingkat persepsi didapat, tahap selanjutnya adalah menguji validitas dan reliabilitas setiap item pertanyaan kuisioner.

Tabel 6. Hasil Uji Validitas Item Pertanyaan tentang Persepsi (p)

\begin{tabular}{llll}
$\begin{array}{l}\text { Item } \\
\text { Pertanyaan }\end{array}$ & $\begin{array}{l}\text { Nilai } \\
\text { Korelasi }\end{array}$ & $\begin{array}{l}\text { Nilai } \\
\text { R } \\
\text { Tabel }\end{array}$ & Keputusan \\
\hline 1 & 0.804 & 0.325 & Valid \\
\hline 2 & 0.517 & 0.325 & Valid \\
\hline 3 & 0.552 & 0.325 & Valid \\
\hline 4 & 0.481 & 0.325 & Valid \\
\hline 5 & 0.687 & 0.325 & Valid \\
\hline 6 & 0.656 & 0.325 & Valid \\
\hline 7 & 0.536 & 0.325 & Valid \\
\hline 8 & 0.460 & 0.325 & Valid \\
\hline 9 & 0.612 & 0.325 & Valid \\
\hline 10 & 0.714 & 0.325 & Valid \\
\hline 11 & 0.492 & 0.325 & Valid \\
\hline 12 & 0.629 & 0.325 & Valid \\
\hline 13 & 0.745 & 0.325 & Valid \\
\hline 14 & 0.786 & 0.325 & Valid \\
\hline 16 & 0.638 & 0.325 & Valid \\
\hline
\end{tabular}

Berdasarkan tabel diatas dapat diketahui bahwa dari 16 item instrumen pertanyaan yang telah diuji tingkat kevaliditasnya, terdapat 16 item pertanyaan yang datanya valid. Data yang tidak valid, tidak akan dipakai pada tahap pengukuran selanjutnya. Dalam menguji validitas item pertanyaan, peneliti menggunakan bantuan program SPSS ke-23 dengan pertimbangan kaidah keputusan Product Moment, bahwa jika, $n_{\text {korelasi }} \leq r_{\text {tabel }}$ berarti tidak valid dan jika $n_{\text {korelasi }}>r_{\text {tabel }}$ berarti valid. 
Tabel 7. Hasil Uji Reliabilitas Item Pertanyaan tentang Persepsi (p)

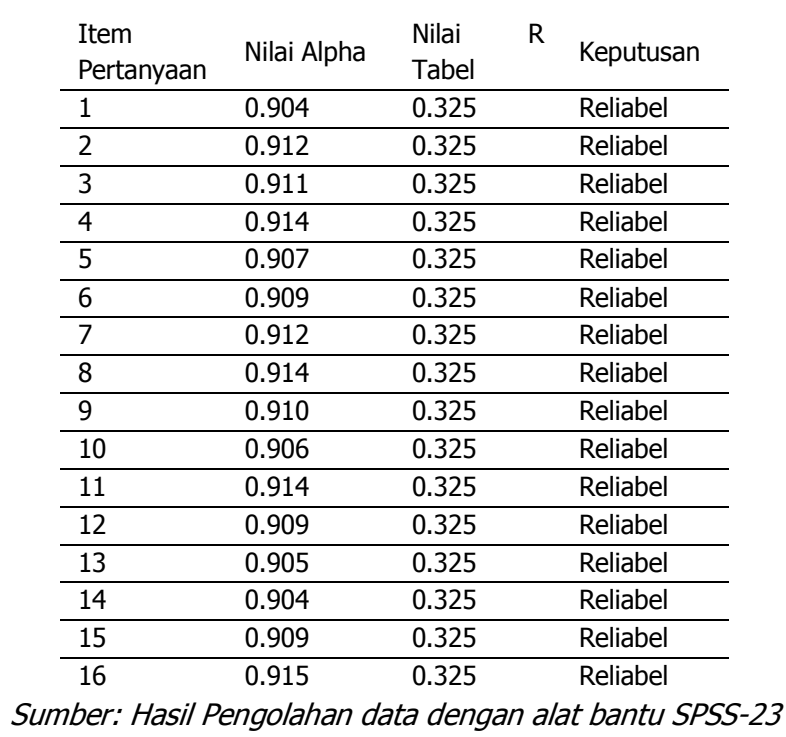

Berdasarkan hasil uji reliabilitas pada tabel diatas menunjukkan bahwa semua item instrumen pertanyaan dinyatakan reliabel. Dalam menguji reliabilitas item pertanyaan, peneliti menggunakan bantuan program SPSS ke-23 dengan pertimbangan kaidah keputusan bahwa jika Nilai Alpha $\leq r_{\text {tabel }}$ berarti tidak valid dan jika Nilai Alpha $>r_{\text {tabel }}$ berarti Reliabel.

\section{Analisis Penilaian Data Berdasarkan Quartil}

Pada tahap ini, data responden terhadap indikator Kepentingan ( $k$ ) dan Persepsi ( $p$ ) dinyatakan kedalam pengukuran kuartil yang tujuannya adalah untuk mencari total skor yang memiliki makna negatif atau positif. Untuk mencari nilai kuartilnya dapat melakukan Cara perhitungannya sebagai berikut:

1. Mencari Batas Bawah (BB), yaitu nilai skor terendah (1) dikalikan dengan jumlah variabel dan dikalikan lagi dengan jumlah responden

2. Mencari Batas Atas (BA), yaitu nilai skor tertinggi (5) dikalikan dengan jumlah variabel dan dikalikan lagi dengan jumlah responden.

3. Mencari Range ( $n$ ), yaitu Batas Atas (BA) dikurangi Batas Bawah (BB)

4. Menentukan Quartil dengan rumus:

$$
Q X=\frac{B B+n \cdot x}{4}
$$

Keterangan:

$\begin{array}{ll}Q X & =\text { Quartil ke } \mathrm{x} \\ B B & =\text { Batas Bawah } \\ n & =\text { Range }\end{array}$

Tabel 8. Hasil Penghitungan Skor Berdasarkan Quartil

\begin{tabular}{lll} 
Komponen & Kepentingan $(\mathrm{k})$ & Persepsi $(\mathrm{p})$ \\
\hline Jumlah Responden & 39 & 39 \\
\hline Total Skor (TS) & 1986 & 1951 \\
\hline Batas Bawah (BB) & 546 & 624 \\
\hline Batas Atas (BA) & 2730 & 3120 \\
\hline Range (n) & 2184 & 2496
\end{tabular}




\begin{tabular}{lcc} 
Quartil 1 & 1092 & 1248 \\
\hline Quartil 2 & 1638 & 1872 \\
\hline Quartil 3 & 2184 & 2496 \\
& Sumber: Hasil Analisis Penelitian
\end{tabular}

Berdasarkan hasil perhitungan diatas, diketahui bahwa penilaian data dapat dinyatakan maknanya sebagai berikut:

1. Jika Total Skor $=\mathrm{BB} \mathrm{s} / \mathrm{d}<\mathrm{Q} 1$ : dengan makna Sangat Tidak Berhasil

2. Jika Total Skor $=\mathrm{Q} 1 \mathrm{~s} / \mathrm{d}<\mathrm{Q} 2$ : dengan makna Tidak Berhasil

3. Jika Total Skor $=\mathrm{Q} 2 \mathrm{~s} / \mathrm{d}<\mathrm{Q} 3$ : dengan makna Berhasil

4. Jika Total Skor $=\mathrm{Q} 3 \mathrm{~s} / \mathrm{d}<\mathrm{BA}$ : dengan makna Sangat Berhasil

Setelah hasil penghitungan skor didapat, maka selanjutnya adalah dapat menentukan hasilnya berdasarkan diagram quartil dibawah ini:

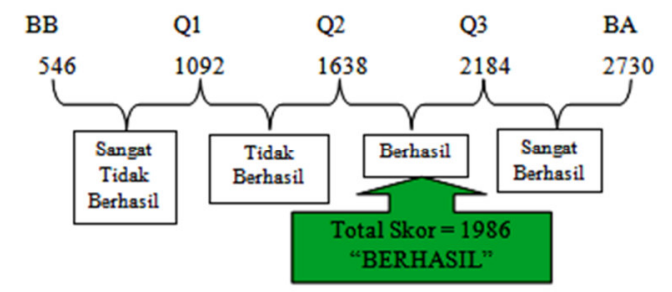

Diagram 1.1. Hasil Quartil Tingkat Kepentingan (k) Responden

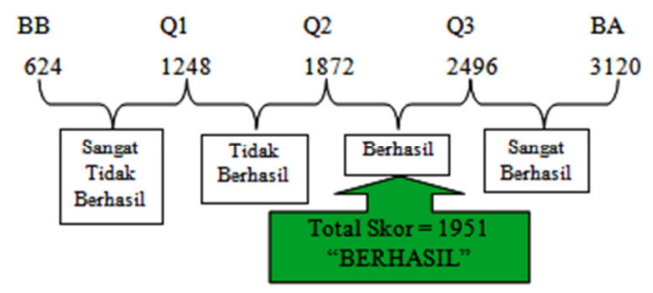

Diagram 1. Hasil Quartil Tingkat Persepsi (p) Responden

Berdasarkan tabel diatas dapat disimpulkan bahwa Tingkat Kepentingan (k) responden terhadap Lapangan Benteng adalah BERHASIL dan Tingkat Kepuasan persepsi (p) responden terhadap Lapangan Benteng adalah BERHASIL.

\section{Kesimpulan}

Berdasarkan hasil pembahasan dan analisis data terhadap 39 responden, maka dapat disimpulkan beberapa hasil temuan persepsi masyarakat terhadap keberhasilan Lapangan Benteng sebagai Ruang Terbuka Publik adalah sebagai berikut:

1. Pengunjung yang sering melakukan aktifitas di Lapangan Benteng Medan merupakan Laki-laki 84.6\% dengan usia rata-rata 15-25 tahun dengan pendidikan terakhirnya adalah SMA/Sederajat yang merupakan mahasiswa yang berstatus kependudukan Tetap di Medan dengan lama tinggal > 16 tahun. Waktu kunjungan yang sering dilakukan adalah pada saat sore hari (16.00-18.00) ketika hari libur besar. pengunjung mendapatkan kendala yaitu tidak bebasnya masuk ke dalam, karena setiap gerbang selalu tertutup.

2. Hasil penilaian persepsi masyarakat pada variabel indikator pada tingkat kepentingan menunjukkan makna penilaian "BERHASIL". Hal tersebut sangat penting untuk Ruang Terbuka Publik khususnya Lapangan Benteng Medan, yang seharusnya memiliki tingkat kebersihan, teduh, sejuk fasilitasnya lengkap, nyaman, mudah dicapai, menarik, ramai dan layak untuk digunakan serta menyenangkan. 
3. Berdasarkan hasil penilaian persepsi masyarakat tentang Keberhasilan Lapangan Benteng Medan terhadap tingkat kepuasan pengunjung ke Lapangan Benteng Medan menunjukkan hasil "BERHASIL". Hal ini menunjukkan bahwa Lapangan Benteng Medan memiliki tingkat penilaian positif terhadap kebersihan, teduh, sejuk, lahan parkir tersedia, nyaman, mudah dicapai, menarik, ramai pengunjung, layak untuk digunakan, serta menyenangkan.

Berdasarkan kesimpulan yang dikemukakan diatas, berikut ini adalah beberapa saran yang nantinya dapat dijadikan sebagai bahan pertimbangan bagi Dinas Pertamanan Medan dalam kaitannya dengan persepsi masyarakat terhadap keberhasilan Lapangan Benteng sebagai Ruang Terbuka Publik. Adapun saran yang dapat peneliti sampaiakan antara lain sebagai berikut:

1. Ketidakbebasnya masuk ke dalam Lapangan Benteng Medan yaitu jangan selalu pagarnya ditutup apalagi dikunci, pengunjung merasa takut masuk sebaiknya dibuat jadwal berkunjung agar tetap teratur dan tercipta keamanan.

2. Dengan hasil penelitian ini diharapkan Ruang Terbuka Publik ini yaitu Lapangan Benteng Medan agar ditingkatkan lagi agar lebih sangat berhasil, baik dari segi akses dan manfaat ruang terbuka publik di kota.

3. Adapun harapan untuk kemajuan Lapangan Benteng ini agar ramai dan selalu digunakan masyarakat yaitu melengkapi hal-hal kebutuhan yang berperan dalam ruang terbuka publik kota yaitu tersedianya fasilitas seperti mushollah, toilet, makanan/minuman, serta permainan anak.

\section{Daftar Pustaka}

Budihardjo Eko \& Sujaro Djoko (1999), Kota Berkelanjutan. Bandung: Penerbit Alumni, Carmona et al (2003), Public Places Urban Spaces. The Dimension of Urban Design, Oxford: Architectural Press. M.T, Drs. Paulus Haryiono (2007), Sosiologi Kota Untuk Arsitek, Jakarta: Bumi Aksara.

Prof. Dr. Ir. Rianse Usman (2012), M.S.Abdi, S.P., M.P. Metodologi Penelitian Sosial dan Ekonomi (Teori dan Aplikasi), Bandung: Penerbit CV Alfabeta,

Stephen Carr dkk (1992), Public Space, Cambrigde University Press, Second Printing.

Sirvani Hamid (1985), The Urban Design Process. New York, Van Nostrand Reinhold Co, New York,

Hariz, Aulia (2013), Evaluasi Keberhasilan Taman Lingkungan di Perumahan Padat sebagai Ruang Terbuka Publik Studi Kasus: Taman Lingkungan di Kelurahan Galur, Jakarta Pusat, dalam Jurnal Perencanaan Wilayah dan Kota, Vol. 24 No. 2.

Jannah Tri Zahrotul (2012), 'Hubungan Persepsi Siswa Tentang Komunikasi Interpersonal Guru-Siswa dengan Motivasi Belajar Siswa Kelas V Sekolah Dasar Negeri Sokanegara II Purwokerto', Program Studi Pendidikan Guru Sekolah Dasar Jurusan Pendidikan Pra Sekolah dan Sekolah Dasar Fakultas Ilmu Pendidikan, Universitas Negeri Yogyakarta.

Rahmawati A. Lucy (2010), 'Citra Lapangan Merdeka Medan Menurut Apresiasi Perempuan'. Program Studi Teknik Arsitektur Bidang Kekhususan Manajemen Pembangunan Kota Universitas Sumatera Utara. 